\title{
Review Essay / Excuse Theory Through a Liberal Lens
}

\author{
Jeremy Horder, Excusing Crime \\ Oxford: Oxford University Press, 2004, $x x+295$ pp.
}

RICHARD C. BOLDT

One good way to size up a new book is to imagine the author's intended audience and purpose. In his introduction to Excusing Crime, ${ }^{1}$ Jeremy Horder, Reader in Criminal Law and Tutor in Law at Worcester College, Oxford, saves his reader the trouble of such imagining by telling us that the "arguments offered" in the volume "are firmly within the tradition of so-called 'analytic', or-more correctly-'applied ethical' thinking about law, and they are in that respect aimed at judges in the higher courts, and at other law reforming bodies, as well as at law students." [5] Horder's project is to build a complex taxonomy of criminal law excuse practices and to use that account of "why things are as they are" to argue, on the basis of his version of liberal theory, against "the restricted range" of excuses in the United Kingdom and elsewhere. [1] As someone who teaches and writes about criminal law in a United States law school, reading Excusing Crime was a little like listening in on a fascinating conversation at a nearby table in a crowded restaurant. The law students Horder has in mind are undergraduates for whom philosophical analysis of the sort he undertakes is less foreign than it would be for the great run of students at American law schools. ${ }^{2}$ His interlocutors-those with whom he imagines himself in conversation-mostly are British academics, including John Gardner, Timothy Macklem, Alan Norrie, and Andrew Ashworth. The book does contain references from time to time to American criminal law theorists,

Richard Boldt is Associate Dean and Professor of Law at the University of Maryland School of Law. including Michael Moore, Joshua Dressler, Heidi Hurd, and George Fletcher, but the overwhelming center of gravity is plainly on the other side of the Atlantic. So too, the great bulk of legal authority under study consists of U.K. cases and statutes and, occasionally, law reform commission proposals. There are, at best, passing references to U.S. cases, and only a few targeted discussions of the Model Penal Code.

Horder's basic framing of his taxonomic project is also characteristic of English rather than American thinking. Excuses, he tells us, excuse wrongful conduct "by shedding favourable moral light on what D did through a focus on the reasons that $\mathrm{D}$ committed that wrongdoing, where those reasons played a morally 'active' role in D's conduct (meaning that what D did or what happened to D can be subject to critical moral evaluation)." [9] This emphasis on the "morally active" reasons for an actor's conduct, which is central to Horder's notion of excusing, may incline some readers to think about the normative judgments inherent in justification defenses, and Horder's taxonomy acknowledges that some excusesthose characterized by strong "actively justificatory" elements ${ }^{3}$ - may come very close to being justification claims. [49] In addition, the requirement that excuses must be grounded in "morally active" reasons serves to exclude claims of non-responsibility that many U.S. theorists regard as legitimate excuses, including insanity and infancy defenses, precisely because these nonresponsibility claims involve reasons for action with respect to which the actor is "morally passive." [9] To be sure, Horder's complex analytic system includes some qualifying excuses-those which are "capacity based"that come very close to being claims of non-responsibility, 
but his insistence on including a normative element ultimately distinguishes these excuses from pure claims of non-responsibility. ${ }^{4}$

Criminal law scholars in the United States generally do not line up the pieces in this fashion. On the one hand, they often think about justification defenses and excuses as more discontinuous than Horder does. On the other hand, though there is no absolute uniformity on this point, most American criminal law theorists regard non-responsibility claims such as insanity and infancy to be complete excuses. As to the first point, U.S. scholarship on the distinction between justification and excuse has become something of a cottage industry. ${ }^{5}$ Although there are lots of variations on the theme, these writers generally take the position that justified actions are not wrongful, whereas excused conduct is wrongful behavior that is exempt from punishment either because the actor's characteristics or the circumstances in which he or she acted render that conduct not culpable. ${ }^{6}$ With respect to capacity-based non-responsibility claims, American writers generally do not insist that an actor's conduct be grounded in morally active reasons in order to qualify for an excuse. Sanford Kadish's widely cited article on criminal law excuses, for example, explains that "the disabilities of choice that ground excuse in our law seem to fall into one of three groups": those disabilities that produce "involuntary actions"; those that produce "deficient but reasonable actions"; and those that render all actions non-responsible. The excuses in Kadish's third category are defined in terms of the actor's "inadequate capacities for making judgments and exercising choice," and include infancy and legal insanity. ${ }^{7}$

\section{Horder has defined a field of study that is both broader and narrower than many of his readers are likely to expect.}

By virtue of his appreciation that some, but not all, excuses contain justificatory elements, and given his insistence that pure claims of non-responsibility are not excuses, Horder has defined a field of study that is both broader and narrower than many of his readers are likely to expect. ${ }^{8}$ This reconfiguration permits Horder to explore the "theoretical underpinnings" [1] of existing excuses along three intersecting "dimensions," and this expli- cation and elaboration of his taxonomy takes up most of the first half of the volume. The effort provides the reader with new analytic tools to organize and understand the seemingly unruly universe of excusing practices in English and American criminal law, and it is the principal contribution of the book.

The first dimension describes the differences between "explanatory" and "adopted" reasons for an actor's conduct. This dimension is concerned with "the nature of the morally salient moving force or motivating element behind D's conduct." [45] Adopted reasons are reasons upon which an actor "positively chooses" to act. Explanatory reasons, by contrast, are reasons for a person's conduct that he or she does not consciously adopt as the grounds for his or her action, but which nevertheless can be said to remain subject to moral evaluation. [10] One possible example of an excuse based upon an adopted reason is what Horder calls "excessive defence" and what some U.S. courts term imperfect self-defense. ${ }^{9}$ In these cases, the defendant claims an excuse or partial excuse, notwithstanding that he or she has used more force than was reasonably necessary to fend off an unlawful attack, on the grounds that "the sheer strength of D's fear made the choice of a heavy-handed course of action as a means of thwarting an attack seem entirely rational and proper." [13] A second example of an excuse centered on an adopted reason is a mistake-of-fact claim based upon a defendant's conscious choice to engage in wrongful conduct because of a mistaken belief that circumstances were such that that conduct was permissible. By contrast, an excuse growing out of a predominantly explanatory reason for a defendant's conduct "comes close to a plea that the conduct is involuntary." [47] If the conduct is a product of the effort or determination of the actor, ${ }^{10}$ however, even "when D 'instinctively' raises an arm to shield him- or herself when V suddenly advances with a raised fist, or spontaneously 'explodes with rage' and lashes out when $\mathrm{V}$ provokes him or her," the conduct is still subject to moral evaluation and is still potentially eligible for an excuse (rather than a claim of non-responsibility). ${ }^{11}$ [47] The distinction between adopted and explanatory reasons is important in Horder's account in a number of respects, but perhaps nowhere more so than with regard to provocation. Thus, when a homicide defendant "decides to make his or her anger grounds for retaliation"- that is, when retaliation stemming from extreme anger is the defendant's adopted reason for actionHorder believes that the claim for a partial excuse of provocation is weaker than when "a loss of self-control is merely the explanatory reason for the retaliatory conduct." [12] 
The second dimension described by Horder concerns the nature of the actor's perspective at the time of wrongdoing. In Horder's terms, a claim to excuse is "actively justificatory" if the actor's decision to act was based upon a contemporaneous belief that he or she was factually or morally justified. Of course, this claim is not that the defendant really was justified in doing what he or she did, but only that he or she believed that the conduct was the right thing to do. By contrast, other claims to excuse, which Horder calls "capacity based," while acknowledging that the defendant was aware at the time of acting that he or she was not justified, provide a partial or complete defense on the grounds that the defendant's capacity to avoid wrongdoing was limited in a way that sheds favorable moral light on his or her conduct. With respect to actively justificatory excuses, in which the defendant believed that his or her conduct was either factually or morally justified, a missing element defense may be available if the defendant's honest belief "negatives" a required mental element in the charged offense. ${ }^{12}$ Horder points out, however, that some criminal statutes require a mistake of fact to be both honest and reasonable in order to serve as the basis of a complete defense. In these cases, he suggests, the objective reasonableness requirement "shows that it [the mistake claim] is really doing excusatory work respecting wrong." ${ }^{13}$ [49] Other excuses are based upon the assertion that "no more could reasonably have been expected of $\mathrm{D}$, in terms of courage, powers of self-control, or of foresight," notwithstanding the fact that the defendant was aware at the time of acting that the conduct was wrongful. [5051] These capacity-based excuses include some types of provocation, duress, and diminished capacity. It may also be possible to combine actively justificatory and capacity-based elements in a single excuse claim. Thus, although much duress doctrine is limited to capacitybased conceptions about what could reasonably be expected of an ordinary courageous person under the circumstances, it would not be incoherent, Horder suggests, to require a showing that, at the time of acting, the defendant also mistakenly believed that his or her conduct was justified.

The third and final dimension described in Horder's taxonomy of excuses concerns the grounds on which a defendant's conduct may be "viewed in a favourable moral light." This dimension operates by way of a distinction between "predominantly ascriptive" grounds for such an evaluation versus a "predominantly normative basis for so doing." [52-53] Horder constructs this distinction around the work of Joseph Raz, who has suggested that "[n]ormative theory is primarily concerned with establishing what people ought to do" whereas " $[t]$ he theory of ascription is concerned with the conditions in which blame or guilt can be ascribed to people."14 [53] Horder demonstrates the distinction between predominantly ascriptive and normative grounds for excuse in the context of duress cases. He begins by observing that all duress defenses have "at least one ascriptive aspect to them," which is the capacity of significant fear to "alter the balance of reasons in D's mind, so that he or she understandably gives priority to saving him- or herself, if need be by committing the wrong in question." In predominantly ascriptive forms of duress, there may be very little else to say about the defendant's conduct, except that we do not blame him or her "at all, or at least not all that much, for giving in to certain kinds of threats by doing certain kinds of wrongs." ${ }^{15}$ [58] In other circumstances, however, we can understand duress as predominantly normative in nature. Suppose, for example, that a defendant faces a choice between submitting to a credible threat of death on the one hand, or giving in to a demand to invade a minor property interest held by an innocent third party on the other. Horder points out that a decision to invade the minor property interest in this case can be treated as a justified instance of necessity. If, however, the choice is between a threat of death on the one hand and a non-deadly assault on an innocent third person on the other, the choice-ofevils defense may slide into an excuse claim for duress, depending upon the relative harm directed against the innocent. In such cases, Horder suggests, when it can be said that a defendant's reaction to the pressing danger "did not go far beyond what was truly justified," the duress defense will be predominantly normative in nature. [59] As he puts it: "Even when D inflicts an unjustified harm on an innocent $V$, crucial to D's excuse can be the claim that there was at least a kind of normative or justificatory 'logic' to D's decision to inflict that (ex hypothesi, minor) harm, particularly if $\mathrm{D}$ did so to avoid certain death him- or herself." [62]

After setting out in detail the three dimensions comprising his taxonomy, Horder begins to map various excuses according to the coordinates he has identified. This portion of the book is a challenging read, as the following passage demonstrates:

Individual excuses can be differentiated from one another in each dimension, as can different manifestations of the same excuse; and there is a surprising amount of variation. Let me give some examples. Excessive defence and most duress cases involve adopted, actively justificatory reasons 
for action (dimensions 1 and 2), and have a predominantly normative basis (dimension 3). If an excuse claim is predominantly ascriptive in character (dimension 3 ), it may also be capacity-based, as in the cases of provocation, clumsiness, due diligence or diminished capacity, but that is not always so. [63]

Notwithstanding some unwieldiness, the complex, multi-variable nature of this approach is clearly superior at a descriptive level to the alternatives pursued by a number of other theorists. For example, some writers take the position that provocation is primarily justificatory in nature, whereas others argue that it is a partial excuse centered largely on the incapacity of the defendant to control his or her behavior. ${ }^{16}$ Horder's approach, by contrast, permits us to explore the variety of ways in which strong emotions interact with defendants' cognitive deliberative processes to produce wrongful behavior. He points out, for example, that some defendants who experience great anger "still find it possible consciously to act for, or in spite of, certain reasons: the case I have been referring to as one in which people act for adopted reasons." [71] In other instances, the defendant's "absence of full deliberative, rational control" over his or her desire to retaliate "explains why the desire ... is the main ascriptive (excusatory) focus." Horder's multidimensional approach demonstrates "that emotions may find intentional expression in action in different ways, through a distinction between cases in which $\mathrm{D}$ acts for explanatory reasons (when the action is closer to the involuntary end of the spectrum), and cases in which D acts for adopted reasons (when the action is closer to a case in which $\mathrm{D}$ retains full rational control over his or her conduct)." [72]

\section{Notwithstanding some unwieldiness, the complex, multi-variable nature of his approach is clearly superior at a descriptive level to the alternatives pursued by a number of other theorists.}

When Horder turns his attention to making sense of the moral claims embedded in his taxonomy, the payoff for all of his (and his readers') hard work is apparent. As noted earlier, the central moral claim is that excuses excuse wrongful conduct when they shed favorable moral light on that conduct, given the "morally active" reasons for the defendant's behavior. It is relatively easy to understand how a defendant who has acted for adopted reasons that were actively justificatory can make a strong claim in this regard, but things get more difficult when the defendant has acted for explanatory reasons and/or claims an excuse based upon his or her limited capacity to control wrongful conduct. If a defendant has "explode[d] with rage" or has acted "instinctively" in response to a victim's provocative conduct, [47] in what respect can we say that he or she was "morally active" with respect to the reasons for his or her conduct? It is one thing, suggests Horder, to withdraw your hand reflexively from a hot stove. That sort of reaction involves involuntary conduct about which moral evaluation is inapt. It is quite another matter to undertake wrongful conduct because someone has tortured you into compliance by holding your hand to the hot stove. That behavior may be "non-voluntary," says Horder, but it is properly subject to moral evaluation because you have retained full control over the execution of the conduct even as your "deliberative control over whether to engage in that conduct or not, and on what terms, is severely undermined or non-existent." ${ }^{17}[85]$

Just as conduct can be located along a continuum from involuntary to non-voluntary to voluntary-butcoerced to fully voluntary, beliefs and emotions can also be understood in Horder's terms as falling out along a spectrum from involuntariness to full deliberative control. In this respect, Horder rejects the Humean notion that beliefs and emotions are, by definition, always involuntary or passive. Instead, he embraces "empirical research, and a philosophical tradition, that rejects Humean assumptions about human nature, and regards a wide range of (if not all) beliefs and feelings as having a morally 'active' dimension to them." [79] To be sure, beliefs and emotions can be involuntary in the same way that a reflective action is, but only "when they take a very primitive form, when their genesis does not lie in situations with complex social and moral meaning." [79] Far more often, Horder argues, a person's beliefs and feelings are likely to be the product of some degree of "deliberative control" and are likely to be mediated by culture and social context. Thus, even though a defendant has acted on the basis of powerful, and, perhaps, sudden, emotions, we can still undertake a moral evaluation of both the conduct and the emotions that produced it. ${ }^{18}$

Throughout the book, Horder posits a range of possible scenarios about the interaction of affective and cognitive processes, and then offers a series of "applied ethical" 
prescriptions for these various possibilities. For example, Horder suggests that a defendant who has acted on the basis of adopted reasons, but without an actively justificatory perspective, may still have a claim to an excuse on the grounds that intense emotions significantly influenced his or her cognitive deliberations. In these cases, he argues, the actor's moral claim to an excuse should turn on "what is at stake." Thus, although existing provocation doctrine in the United Kingdom and the United States generally assumes that a defendant who acts for adopted reasons is not eligible for a provocation defense, because the cognitive deliberation involved in adopting reasons for action are inconsistent with a loss of self-control, Horder would permit such claims on a sort of sliding scale. As he explains it:

In a provocation case where $\mathrm{D}^{\prime} \mathrm{s}$ anger has taken a form coming closer to the full 'deliberative control' end of the spectrum, we could expressly require more, by way of provocation, than when D's anger spontaneously explodes from within without any element of calculation (the case where D's anger is an explanatory reason for his or her conduct). The fact that $\mathrm{D}$ acts for adopted reasons, in cases where $\mathrm{D}$ is outraged following provocation, means that it would be quite appropriate for the law to insist that $\mathrm{D}$ be responding only to the gravest of provocations in such cases (the retaliatory stakes must be very high), or even to deny $\mathrm{D}$ an excuse altogether; whereas, the law might be understandably less insistent on this point in cases where D reacts immediately and spontaneously to an explosion of passion. [91]

\section{The central moral claim is that excuses excuse wrongful conduct when they shed favorable moral light on that conduct, given the "morally active" reasons for the defendant's behavior.}

The philosophical tradition upon which Horder draws in taking the position that beliefs and feelings, as well as conduct, ought to be the basis for moral evaluation, includes Aristotle, Harry Frankfurt, and Joseph Raz. In this respect, he is in very good company. On the other hand, the empirical foundation upon which his arguments rest is far less clearly realized. What does it mean to say that anger has "spontaneously explode[d] from within without any element of calculation,"19 [91] and how is it that other intense emotions influence rational thinking without causing the actor to bypass cognitive control? At several critical points in the book, Horder cites scientific work on the brain and human emotions. The reader is directed, for example, to a book by Joseph LeDoux entitled The Emotional Brain: the Mysterious Underpinnings of Emotional Life, and to an article by Dolf Zillmann on the role of the limbic system in the evolution of human emotions. ${ }^{20}$ Notwithstanding these passing references, though, Horder does not offer the reader much in the way of a scientific foundation for his otherwise quite nuanced account of the complicated ways in which emotion and cognition interact in and through the human brain. This is too bad, because there is a growing body of literature in the area of brain science, the emotions, and cognition that is relevant to Horder's project. ${ }^{21}$

In contrast to the very sketchy empirical foundation provided in the book, Horder's argument for the development (or expansion) of three new excuses is carefully grounded in a well worked-out account of liberal political theory. He frames this part of his enterprise by first distinguishing between what he calls the "necessary" as opposed to "sufficient" conditions for a successful excuse claim. Not surprisingly, given Horder's central moral claim, the necessary condition is the presence of an explanation for wrongdoing "that sheds such a favourable moral light on D's conduct that it seems entirely wrong to convict, at least for the full offence." [9] In effect, the necessary condition focuses on the moral claims of an individual to be free from punishment (or to receive mitigated punishment), given the morally active reasons for his or her conduct. The sufficient conditions, by contrast, grow out of Horder's assessment of the community's collective interests in the fair and effective operation of the criminal law. These conditions operate to limit individual claims to excuse that satisfy the necessary condition but that are inconsistent with broader common goods. ${ }^{22}$ Among Horder's sufficient conditions are strategic and common goods concerns that relate to the fit between legal prohibitions and secular morality, the legitimacy of the criminal law and the community's interest in "a culture of compliance and law-abidingness," fairness, system administrability, and the proper allocation of decision-making authority among governmental actors given the relative institutional competencies of the legislature and the courts.

Horder argues that H.L.A. Hart's account of excuse theory is over-broad in that it concentrates on the necessary condition for excuses to the virtual exclusion of any consideration of sufficient conditions. He is wise to sug- 
gest that the failure of Hart and others to limit excuses by reference to a set of strategic or common goods criteria has placed considerable pressure on policy makers and scholars to adopt a relatively pinched view of the range of reasons that might otherwise count as meeting the necessary condition for an excuse. In this light, Horder argues that the predominant conception of excuses within the common law, which he calls the classical theory of excuses, is over-narrow. To take Hart's formulation, excuses under the classical conception are focused on "rational defects in any morally salient 'moving force' behind the act or omission." [43] Horder criticizes this conception in part on the grounds that wrongdoing ought to be excusable in certain circumstances even when no such rational defect is present. That is, an excuse should still be possible even when the grounds for the defendant's claim are predominantly normative rather than ascriptive in nature. In addition, he argues against the tendency of adherents of the classical theory to distinguish sharply between defendants who have rational defects and those who have claims of non-responsibility. The former criticism of the classical view leads Horder to propose new excuses for "due diligence" and for "demands-of-conscience." The latter critique is the basis for his proposal for a partial excuse for "short-comers," that he terms "diminished capacity."

\section{Horder argues that the predominant conception of excuses within the common law is over-narrow.}

The point of departure for Horder's discussion of all three of these new excuses is Ronald Dworkin's famous injunction that the state has an obligation to treat people with equal concern and respect, "where to treat people with concern is to treat them 'as human beings who are capable of suffering and frustration', and to treat them with respect is to treat them 'as human beings who are capable of forming and acting on intelligent conceptions of how their lives should be lived.'"23 [141] The liberal commitment to treating people with concern, Horder suggests, may require that some defendants, who by virtue of "shortcomings" not rising to the level of insanity are not fully able to regulate their conduct, be accorded a partial excuse in some circumstances. By contrast, the classical view that individuals are either fully responsible moral agents or entirely non-responsible for their conduct, is incapable of taking into consideration, except at sentencing, the sorts of individualized deficits that Horder has in mind. Thus, subject to the strategic and common goods limitations imposed by his sufficient conditions, Horder's proposal contemplates providing a "diminished capacity" plea $^{24}$ to some defendants who suffer from deficiencies that do not wholly undermine responsibility, when these defendants find themselves in circumstances that contain an incipient or incomplete excusatory factor.

Horder provides a series of very interesting examples of how this mixing of oil (excuse) and water (mental deficiency) would function. He begins with cases of family violence, in which a defendant who has endured abuse at the hands of a partner or parent finally employs deadly force to escape the escalating battering or psychological abuse. While a self-defense defense is often available, Horder focuses on cases in which a true justification defense may be inappropriate. In $R v$. Ahluwalia, ${ }^{25}$ for example, the defendant, who suffered from "endogenous depression," killed her abusive husband by setting fire to him as he slept. No self-defense plea was raised, presumably because there was "considerable evidence of advance preparation for an attack of a specific kind (burning), and because D admitted in a letter to her mother that the reason she had set fire to $\mathrm{V}$ was to give him 'a fire bath to wash away his sins.'" Nevertheless, Horder suggests that "the combination of evidence of mental disorder and evidence of extraordinary external pressure is sufficient to justify a judgment that a first-degree conviction would be wrong, and a partial excuse by way of diminished capacity would be more appropriate." [181]

Horder also discusses self-defense cases in which evidence of mental deficiency could be made relevant to a partial excuse, notwithstanding the defendant's use of excessive force. Thus, in $R v$. Martin (Anthony), ${ }^{26}$ the defendant who employed excessive or unreasonable selfdefensive force was suffering from clinical depression that aggravated a paranoid personality disorder. Apparently, there was expert testimony that the defendant's personality disorder could have led him "to perceive the threat to his safety to be much greater than an ordinary person would have thought that it was." [182] Under existing law in the U.K. and most U.S. jurisdictions, the depression and personality disorder probably would not be sufficient to support an insanity defense, and the defendant's idiosyncratic characteristics would not be taken into account in determining the reasonableness of his perception of necessity. Under Horder's short-comers approach, by contrast, the evidence would be admissible 
for purposes of evaluating a partial excuse of diminished capacity.

Finally, Horder discusses the use of his proposed diminished capacity defense in some cases involving defendants with deprived backgrounds. He points out that

[b]oth biological and environmental factors may combine to create ... pressures, in different ways, perhaps particularly in young people when the influence of attention deficit disorder, hyperactivity, and low IQ are met with long-term parental indifference or hostility; and the influence of the environmental factors in the mix has been shown to be aggravated by the effects of social and economic deprivation. [187]

\section{Horder makes out a case for the recognition of a due diligence excuse in the area of regulatory offenses, when the defendant has "done everything humanly possible to avoid wrong-doing."}

Horder suggests that these sorts of deficits occasioned by social and economic deprivation, when combined with some external elements such as threats or provocation, may support a partial excuse claim under some circumstances. Although it is common for courts and commentators to suggest that the effects of deprivation are best taken into consideration in sentencing, Horder argues that a defendant whose capacity to navigate trying circumstances was substantially diminished at the time of an offense, is treated with equal concern only when that fact is made relevant to an assessment of the level of his or her criminal guilt. In this respect, Horder's use of liberal theory as the foundation for his approach to shortcomers is quite interesting. A number of commentators over the past decades have decried "the modern tendency to view the self as a machinery to be maintained and repaired by specialists and to rethink what was once known as 'evil' in terms of pathology rather than moral choice'." ${ }^{27}$ Horder's approach appears to avoid these kinds of dehumanizing tendencies inherent in the rehabilitative ideal while still taking seriously Dworkin's injunction to treat short-comers "as human beings who are capable of suffering and frustration." It does so by refusing to exempt these actors from moral judgment while simultaneously acknowledging that "they may be, in some circumstances, just as deserving as the mentally well-equipped with their own partial excuse claims, of some punishment, but also of mitigation and leniency, pure and simple, irrespective of considerations of 'maintenance and repair'." [143]

When Horder turns his attention in the final two chapters of the book to the excuses of due diligence and demands-of-conscience, he shifts from Dworkin's notion that the state has an obligation to treat people with concern and concentrates instead on the state's obligation to treat people with respect. Importantly, respect in these terms requires the state to recognize that defendants are "human beings who are capable of forming and acting on intelligent conceptions of how their lives should be lived." [141] Horder's project in this respect is to create enough "excusatory space" to support the liberal values of personal autonomy and tolerance of moral pluralism while still safeguarding societal strategic interests and common goods through a consideration of sufficient conditions. The demands-of-conscience cases involve circumstances in which the defendant is forced to choose between law abidingness and adherence to important moral or religious beliefs that conflict with a law of general application. Horder suggests that when such conflicts arise, the defendant should be permitted an excuse if his or her decision to engage in wrongful conduct, ${ }^{28}$ judged from the point of view of the law of general application, was a "relatively trivial legal demand" compared to the strength or importance of the contrary personal belief. To hold otherwise, he argues, would be "to place disproportionate emphasis on the importance of law-abidingness" as against the competing liberal values of personal autonomy and moral pluralism. [199] Horder's development of this approach is quite nuanced. He acknowledges, for example, that there is an important difference between those who engage in lawbreaking as a "calculated act of defiance" and those who do so "more or less spontaneously" out of a "sense of moral obligation." [200-201] He also works out in some detail where his proposal stands relative to the broader tradition of civil disobedience. This is good work precisely because it goes beyond a flat account of individual rights and explores instead both the individual and collective interests that are at stake in the cases he has in mind.

In the book's concluding chapter, Horder makes out his case for the recognition of a due diligence excuse in the area of regulatory offenses, when the defendant has "done everything humanly possible to avoid wrongdoing." [4] Horder's starting point here is the observation 
that judges and commentators have unduly narrowed the range of possible excuses by failing to consider fully moral claims to exculpation in the context of the "bureaucratic-administrative state." [237] He credits the Canadian Supreme Court in $R v$. City of Sault Ste Marie ${ }^{29}$ with showing the way toward such an excuse by permitting a defense in a strict liability case "if D could show on the balance of probabilities that he took all reasonable care," [239] and he broadens the analysis by including the possibility as well that reasonable ignorance of the law might also be the basis for an excuse. While the insights Horder offers in this chapter are not as novel as those provided in the context of his discussion of the short-comers and demands-of-conscience excuses, his analysis is still compelling and useful. He argues, in effect, that the common good of reciprocity requires that the legal system make both substantive and procedural opportunities available to defendants to answer for their wrongs. "If, whatever efforts one may have made or precautions one may have taken, there is simply no answer one can make to a criminal charge, the substantive fairness of one's trial is threatened, in that one has no self-sufficient moral reasons, qua individual $\mathrm{D}$, to engage constructively and co-operatively in the trial process." [255]

In his consideration of all three of these excusesshort-comers, demands-of-conscience, and due diligence - Horder achieves his broader purpose of showing how a detailed and complex understanding of existing excuse practices supports the extension of available excusatory space, subject to the important limits imposed by his sufficient conditions. This careful use of description and analysis to construct an "anatomy" of existing excuses in order to support claims for new excuses is the best kind of criminal law scholarship. The book is certainly not an easy read, but it is well worth the trouble.

\section{NOTES}

1 Jeremy Horder, Excusing Crime, Oxford: Oxford University Press, 2004. [Bracketed page numbers in text and footnotes refer to this book.]

2 Horder is convinced that his effort is neither too detailed for busy judges, too abstract for policy makers, nor "too difficult for the average undergraduate law student." Instead, he suggests that English criminal court judges already are engaged in thinking about criminal law theory and English law students are "at least as intelligent and well-qualified, at the point of entry to university, as undergraduate philosophy students." [5]

3 An excuse is "actively justificatory" in Horder's taxonomy when the defendant subjectively believed at the time he or she acted that his or her conduct was justified, even though it is later determined that the defendant's honest belief was unreasonable. [49]

4 So, for example, "however persistent the 'provocation' one should never be excused for violently expressing one's temper by harming a crying baby," but one might succeed in interposing a non-responsibility claim of insanity under very similar circumstances. [58]

5 See sources cited in Mitchell N. Berman, "Justification and Excuse, Law and Morality," Duke Law Journal 53 (2003): 8 n. 12.

6 See, e.g., Kent Greenawalt, "The Perplexing Borders of Justification and Excuse," Columbia Law Review 84 (1984): 1897; Heidi M. Hurd, "Justification and Excuse, Wrongdoing and Culpability," Notre Dame Law Review 74 (1999): 1551. By contrast, Horder takes the position that, though some excuses come close to justification claims because they contain strong actively justificatory elements, true justification claims still involve instances of wrongdoing, albeit "justified wrongdoing." [101]

7 Sanford H. Kadish, "Excusing Crime," California Law Review 75 (1987): 258-262. See also, Joshua Dressler, "Forward: Justifications and Excuses: A Brief Review of the Concepts and the Literature," Wayne Law Review 33 (1987): 1166 (discussing how mental illness functions to trigger either the "causation theory" or the "character theory" of excuse).

8 Indeed, Horder makes precisely this claim with respect to H. L. A. Hart's classic formulation of excuse theory. Horder describes Hart's view that "excusing conditions are focused in part on rational defects in any morally salient 'moving force' behind the act or omission" as "in a way too narrow, and in a way too broad an understanding of excuses," because it includes wrongdoing with respect to which the wrongdoer was morally passive and excludes some excuses that do not involve irrationality. [43-44]

9 See, e.g., State v. Faulkner, 483 A.2d 759 (Md. 1984).

10 This useful phrase is taken from the Model Penal Code provision governing voluntary conduct. See Model Penal Code section 2.01(2)(d).

11 "[W]e can still ask whether D should have let his or her temper, or terror, get the better of him or her to the extent that it did." [12]

12 See Model Penal Code, section 2.04(1).

13 A defendant may have an excuse based upon a moral mistake when, for example, the defendant "believed he was fulfilling his or her duty to a sick child by simply praying for the child's recovery." [49] In such cases, the defendant does not have a true justification defense, because his or her moral 
conviction was mistaken; nevertheless, there may be grounds for an excuse within Horder's conception if the mistake sheds a favorable moral light on the defendant.

14 Joseph Raz, Practical Reason and Norms (Oxford: Oxford University Press, 1999), 11-12 [quoted in Horder at p. 53]. Although ascriptive questions often intersect with capacitybased excuse claims, Horder makes clear that they may apply to actively justificatory excuses as well.

15 Horder does identify "a further category of case in which duress cases could be permitted to take a predominantly ascriptive form." These are cases in which "allowance is made, or should be made," for certain characteristics, such as youthfulness, that make the actor more prone to weakness in the face of threats. [63]

16 See, e.g., A. J. Ashworth, "The Doctrine of Provocation," Cambridge Law Journal 35 (1976): 292 ("the claim implicit in partial justification is that an individual is to some extent morally justified in making a punitive return against someone who intentionally causes him serious offence . .."); Joshua Dressler, "Rethinking Heat of Passion: A Defense in Search of a Rationale," Journal of Criminal Law and Criminology 73 (1982): 421 ("It is morally questionable to suggest that there is less societal harm in Victim's death merely because he acted immorally.").

17 Still further up the spectrum, Horder argues, is the case in which the actor engages in wrongful conduct because he or she has been threatened with torture. Thus, if you commit a wrongful act in order to avoid my holding your hand to a hot stove, Horder would say that your compliance is "coerced but it is hardly non-voluntary." [85]

18 So, too, "beliefs, like emotions such as anger and fear, are sensitive to reason and are in that sense part of the 'active' side to our moral nature, subject to evaluative direction or control." [82]

19 This colorful phrase is actually a paraphrase of a formulation offered by Joseph Raz. See, Joseph Raz, Engaging
Reason (Oxford: Oxford University Press, 2002) [cited in Horder at p. 87].

20 Joseph LeDoux, The Emotional Brain: The Mysterious Underpinnings of Emotional Life (New York: Simon \& Schuster, 1996) [cited in Horder at p. 72]; Dolf Zillmann, Our Unique Motives for Violence Sit Beside Archaic Animal Drives for Aggression," Times Higher Educational Supplement, April 12, 2002, 18-19 [cited in Horder at p. 80].

21 See, e.g., Antonio R. Damasio, Descartes' Error: Emotion, Reason, and the Human Brain (New York, G. P. Putnam's Sons, 1994); Michael S. Gazzaniga, The Ethical Brain (New York/ Washington, D.C.: Dana Press, 2005); Allen Newell, Paul S. Rosenbloom, and John E. Laird, "Symbolic Architectures for Cognition," in Foundations of Cognitive Science, ed. Michael I. Posner (Cambridge, M.I.T. Press, 1989).

22 The notion of a "common good" is borrowed by Horder from the work of John Finnis and Joseph Raz. See, John M. Finnis, Natural Law and Natural Rights (Oxford: Clarendon, 1980); Joseph Raz, Ethics in the Public Domain (Oxford: Clarendon, 1994) [cited in Horder at p. 15].

23 Ronald Dworkin, Taking Rights Seriously (London: Duckworth, 1977) [cited in Horder at p. 141].

24 Horder suggests that this partial excuse would function to reduce first-degree offenses to second-degree offenses, much as provocation does in the homicide area. [144-145]

\section{5 [1992] 4 All ER 889.}

26 [2002] 2 WLR 1.

27 David Garland, Punishment and Modern Society (Oxford: Clarendon, 1990) [quoted in Horder at p. 143].

28 Importantly, Horder is talking here only about the possibility of according the demands-of-conscience defendant an excuse, in which wrongdoing is admitted, rather than a justification.

2985 DLR 3d 161 (1978). 